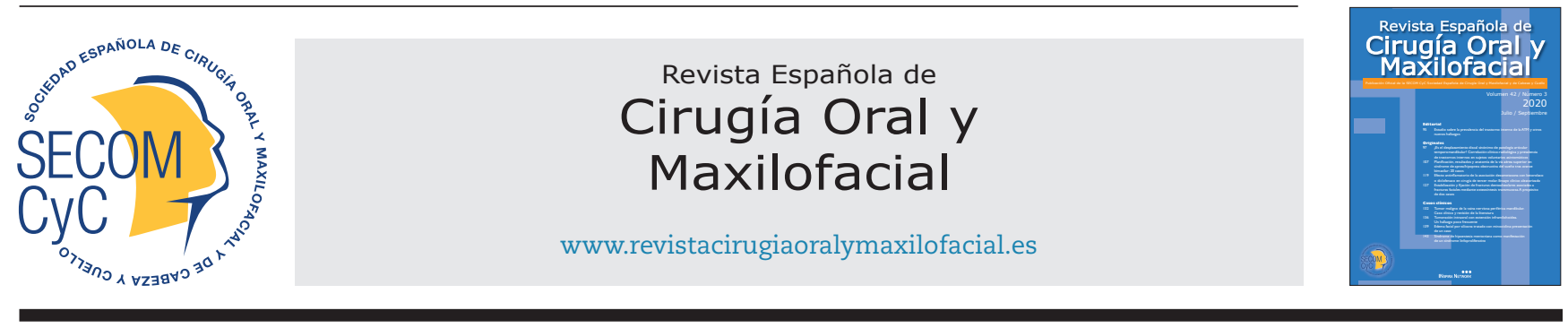

\title{
Editorial
}

\section{Estudio sobre la prevalencia del trastorno interno de la ATM y otros nuevos hallazgos}

El presente número de Revista Española de Cirugía Oral y Maxilofacial (RECOM) aborda, entre otros, dos campos que pueden considerarse en crecimiento por la asociación de técnicas mínimamente invasivas en el caso del trastorno interno (TI) de la articulación temporomandibular (ATM), y por la generación de un relativamente nuevo campo de actuación para el médico especialista en Cirugía Oral y Maxilofacial: la cirugía de avance maxilomandibular en el tratamiento del síndrome de apnea/ hipopnea obstructiva del sueño (SAHOS).

El TI de la ATM se define como la relación anormal entre el disco articular con respecto al cóndilo mandibular, la eminencia articular y la fosa glenoidea, y la mayoría de los autores lo asimilan a desplazamiento discal. De forma intuitiva, el desplazamiento discal podría identificarse con la existencia de sintomatología articular dolorosa, y de hecho el desplazamiento discal está presente en el 80-90 \% de los casos sintomáticos; sin embargo, existen pacientes (por ende, sintomáticos) en los que no se constata la existencia de desplazamiento discal y, por el contrario, individuos asintomáticos en los que se demuestra la existencia de un disco desplazado. Esta heterogeneidad en la presentación del TI obliga a un estudio detallado de la prevalencia de esta entidad en grupos de población sanos, objetivo este escasamente estudiado que abordan los autores del primer artículo original del presente número. Objeto de una tesis doctoral leída en 2014 por parte del autor principal, los autores publican los resultados inéditos derivados del análisis clínico y radiológico de una serie de 72 ATM pertenecientes a sujetos voluntarios asintomáticos, correlacionando la prevalencia de desplazamiento discal con las características clínicas y morfológicas articulares examinadas mediante resonancia magnética nuclear.

El tratamiento del SAHOS experimentó hace ya varios años una revolución al contar con la participación activa del Cirujano Oral y Maxilofacial, sobre todo en pacientes refractarios al tratamiento mediante CPAP (Continuous Positive Airway Pressure), por medio de la indicación del uso de dispositivos de avance mandibular en los casos más leves, y por medio de cirugía de avance maxilomandibular (AMM) para los casos más severos, entre otros procedimientos complementarios. Los autores de uno de los artículos originales de este número presentan los resultados de una serie de 20 pacientes con SAHOS, intervenidos mediante AMM con rotación antihoraria, obteniendo conclusiones clínicas relevantes en términos de disminución del índice de apnea/ hipopnea (IAH) y de aumento de la saturación de oxígeno periférica capilar, evaluados en la polisomnografía, así como cambios morfológicos significativos en los parámetros de incremento de volumen y áreas de la vía aérea y posición del hioides, evaluados por medio de tomografía computerizada.

El número aporta un ensayo clínico aleatorizado doble ciego en 75 pacientes sobre el efecto antinflamatorio del uso de dexametasona y diclofenaco versus dexametasona y ketorolaco en la cirugía del tercer molar. Tratándose del procedimiento quirúrgico aislado más frecuente en número de pacientes tratados dentro de nuestra especialidad, la presentación de nuevo conocimiento con evidencia científica alta es una ayuda inestimable en el establecimiento de protocolos de tratamiento posoperatorio eficaces.

\footnotetext{
*Autor para correspondencia:

Correo electrónico: raulmaxilo@gmail.com (Raúl González-García).
}

DOI: $10.20986 /$ recom.2020.1194/2020

1130-0558/@ 2020 SECOM. Publicado por Inspira Network. Este es un artículo Open Access bajo la licencia CC BY-NC-ND (http:// creativecommons.org/licenses/by-nc-nd/4.0/). 
Finalmente, tratando de mantener el espíritu de la RECOM de aportar nuevo conocimiento por medio de la publicación de casos clínicos especialmente relevantes para el lector desde el punto de vista clínico, o inusitadamente infrecuentes o por medio de técnicas quirúrgicas novedosas, el número aporta nuevos datos sobre el uso de la osteosíntesis transmucosa en el tratamiento de fracturas dentoalveolares, el diagnóstico del tumor maligno de la vaina nerviosa periférica mandibular, del linfangioma con extensión inframilohidea y del síndrome de hipoestesia mentoniana como manifestación de un síndrome linfoproliferativo, y el tratamiento mediante minociclina del edema facial provocado por silicona.

Esperamos que estos artículos originales y nuevos casos clínicos sean del interés del lector especializado, y animamos a los autores (clínicos e investigadores) al envío de sus trabajos a RECOM para seguir creciendo en el objetivo de aportar nuevo conocimiento científico de calidad, como órgano científico de nuestra especialidad a nivel nacional y de todos nuestros hermanos hispanohablantes.

Raúl González-García Director de RECOM. Facultativo Especialista de Área, Hospital Universitario de Badajoz, Badajoz, España. Hospital Quirónsalud Clideba, Badajoz, España 